\title{
PERCEPÇÃO DOS TORCEDORES DE ESTÁDIOS PERIFÉRICOS DIANTE DO PROCESSO DE MODERNIZAÇÃO DOS ESTÁDIOS BRASILEIROS
}

Recebido em: 20/07/2020

Aprovado em: 15/01/2021

Licença:@) (1) @

\author{
Christian Matheus Kolanski Vieira ${ }^{1}$ \\ Sílvio Ricardo da Silva ${ }^{2}$ \\ Universidade Federal de Minas Gerais (UFMG) \\ Belo Horizonte - MG - Brasil
}

RESUMO: Estádios periféricos como o Castor Cifuentes/MG e o Farião/MG, com capacidade inferior a 10 mil presentes, representam $77,4 \%$ do total de estádios brasileiros. Objetivamos aqui analisar a percepção que os torcedores de estádios periféricos têm sobre estádios e arenas. Para tanto, realizamos 19 incursões a campo, todas em dias de jogos. Para busca dos dados utilizamos a observação não participante e aplicação de formulários. Os dados foram analisados através do programa de análises estatísticas Statistical Package for the Social Sciences (SPSS) e da análise de conteúdo. Ao fim, participaram do estudo 107 torcedores. Os resultados obtidos evidenciaram que os participantes são favoráveis a tais transformações, mesmo cientes dos pontos negativos. Inclusive do risco de serem excluídos da vivência cotidiana nos estádios.

PALAVRAS-CHAVE: Futebol. Torcer. Estádio.

\section{PERCEPTION THAT FANS WHO GO TO BRAZILIAN PERIPHERAL STADIUMS HAVE OF BIGGER STADIUMS AND ARENAS}

ABSTRACT: Peripheral stadiums like Castor Cifuentes/MG and Farião/MG, with a capacity below 10.000 people, represent $77.4 \%$ of the total Brazilian stadiums. We aim here to analyze the perception that fans who go to peripheral stadiums have of bigger stadiums and arenas. To do so, we conducted 19 visits to the stadiums, all on game days. Data were collected through non-participant observation and application of forms. Data were analyzed through the statistical analysis program Statistical Package for Social Sciences (SPSS) and content analysis. We had the participation of 107 individual fans. The main results show that fans are in favor of the changes even though they are aware of the negatives, including the risk of being hindered of frequent active life in stadiums.

KEYWORDS: Soccer. Fan. Stadium.

\footnotetext{
${ }^{1}$ Doutorando em Estudos do Lazer pela Universidade Federal de Minas Gerais (UFMG).

2 Docente da Universidade Federal de Minas Gerais (UFMG) e do Programa de Pós-graduação em Estudos do Lazer. Líder do Grupo de Estudos sobre Futebol e Torcidas (GEFUT)
} 


\section{Introdução $0^{3}$}

[...] vai esperar acomodar todo mundo sentado para começar o jogo? Isso não é realidade, não é? Isso aqui não é Copa do Mundo ainda, nem é arena, é diferente, isso é estádio, não é arena. (Roberto Fernandes - Técnico de futebol)

O dia: 05 de outubro de 2013; a ocasião: 27 rodada do campeonato brasileiro de futebol da série B; o local: Estádio Maria Lamas Farache (Frasqueirão) ${ }^{4}$; o jogo: ABC Futebol Clube (ABC-RN) versus Sociedade Esportiva Palmeiras (Palmeiras); o destaque: poderia ter sido as reviravoltas ${ }^{5}$ ocorridas na partida, não foi.

Antes mesmo do apito inicial do árbitro, um fato já chamava mais atenção do que a partida de futebol chamaria naquele dia: A superlotação do estádio. As arquibancadas estavam ocupadas de tal forma, que por questão de segurança a polícia militar orientou parte dos torcedores para que pulassem o alambrado. Ao ser abordado pela imprensa, após a resolução do incidente, o então técnico do ABC-RN, Roberto Fernandes, proferiu a citação que abre este trabalho ${ }^{6}$. Não cabe aqui julgar a opinião do mesmo, mas a reflexão no diz respeito ao processo de modernização (e seus desdobramentos) que vem ocorrendo nos estádios brasileiros.

Com base na citação inicial deste trabalho, especificamente pela afirmação "isso é estádio, não é arena", a priori, as diferenças entre estádios e arenas, bem como as normas de condutas que regem cada um desses espaços, parecem estar claras para os profissionais que atuam diretamente com futebol (como técnicos e dirigentes); mas e para os torcedores? Estes compreendem a lógica citada pelo profissional de que arenas são projetadas para oferecer conforto, ao passo que os estádios não? Quais as

\footnotetext{
${ }^{3}$ Esta pesquisa contou com financiamento do CNPq, na forma de concessão de bolsa de Mestrado.

${ }^{4}$ Localizado na cidade de Natal, capital do Rio Grande do Norte.

5 O ABC-RN, que havia inaugurado o marcador, sofreu a virada do Palmeiras por 2x1, ainda assim reagiu e reverteu o placar. A partida terminou em 3 x 2 a favor do time da casa.

${ }^{6}$ Reportagem disponível em: https://globoplay.globo.com/v/2870858/. Acesso em: 01 jul. 2020.
} 
concepções dos torcedores que frequentam os estádios periféricos, sobre este processo de modernização?

Não há consenso em relação ao ponto que determinaria o início deste fenômeno. Dessa forma, entende-se aqui como processo de modernização dos estádios, a recente conversão (através de obras de infraestrutura) de alguns estádios brasileiros em arenas multiuso. Aos estádios que não passaram pelo processo de transformações e adequações para a Copa do Mundo da Fédération Internationale de Football Association (FIFA) 2014 usamos aqui, neste trabalho, a expressão "estádios periféricos".

O Brasil dispõe de 789 estádios de futebol, de acordo com o Cadastro Nacional de Estádios de Futebol (CNEF) realizado pela Confederação Brasileira de Futebol (CBF) em 2016. A região sudeste lidera, detendo 32,8\% do total, Minas Gerais aparece com $18 \%$ dos pertencentes à região ${ }^{7}$. Apesar de serem aqueles com maior capacidade de público que mais aparecem nas mídias, eles não evidenciam a realidade do contexto brasileiro. Estádios como os da Copa do Mundo de 2014, com capacidade igual ou superior a 40 mil assentos, representam 3\% do total dos estádios brasileiros, de acordo com o CNEF.

Em contrapartida, estádios periféricos como o Waldemar Teixeira de Faria (Farião) e Municipal Castor Cifuentes (Castor Cifuentes) ${ }^{8}$, com capacidade inferior a 10 mil presentes, representam 77,4\% do total. Em Minas Gerais, 73,9\% possuem capacidade inferior a 10 mil pessoas. Tamanha a representatividade deste grupo no cenário nacional, parece equivocada a ideia de que os estádios brasileiros são modernos. De fato, não se pode negar a existência de um processo modernizador em andamento

\footnotetext{
${ }^{7}$ Em valores absolutos, a região sudeste concentra 259 estádios, sendo 46 em Minas Gerais.

${ }^{8}$ Capacidade para 5160 e 4181 torcedores, respectivamente. Ambos localizados em Minas Gerais.
} 
pelo Brasil, entretanto, há que se esclarecer que esse procedimento não contempla os estádios brasileiros em sua totalidade. Pelo contrário.

Trabalhos como o de Campos (2016), Curi (2013), Damo e Oliven (2013) e Mascarenhas (2014) exploram amplamente a temática da modernização dos estádios. Apesar disso, pouco tem sido investigado sobre os torcedores localizados fora do "centro de mudanças" e o que pensam sobre esse processo. Nesse sentido, Costa (2015) exerce importante papel ao dar voz aos "torcedores periféricos", proporcionando melhores condições para gerir tais transformações, além de realizar um importante trabalho de resgate à história dos clubes do interior do Brasil, por vezes esquecidas. Assim, consideramos que este estudo pode fomentar novos olhares às discussões sobre a temática do torcer.

Ainda que não atingidos diretamente pela onda modernizadora, os estádios Farião e Castor Cifuentes já estiveram diante a possibilidade de modernização. Em 2007 a diretoria do Villa Nova Atlético Clube (Villa), o poder público municipal de Nova Lima e os parceiros econômicos do clube se reuniram no sentido de viabilizar a construção da Arena do Leão (FREITAS, 2008). A proposta delineava a construção de um novo estádio, moderno e seguro. O projeto foi concluído e possuía previsão para ser iniciado em 2008; um presente ao centenário da equipe. Em 2012 a prefeitura de Divinópolis apresentou ao conselho deliberativo do Guarani Esporte Clube (Guarani) proposta de revitalização do estádio, incluindo entre outras coisas, elevação da capacidade e colocação de cadeiras nas arquibancadas. Para tanto, seria necessário o clube ceder o estádio para o município.

Esse artigo tem como propósito investigar como se configuram as práticas do torcer pelos torcedores do Villa Nova de Nova Lima e do Guarani de Divinópolis em 
seus respectivos estádios; e, analisar a percepção que os torcedores desses estádios periféricos têm sobre Estádios e Arenas.

\section{Método}

Realizamos incursões a campo nos estádios Farião e Castor Cifuentes ${ }^{9}$. Estes foram escolhidos para a categoria de estádios periféricos, por serem conhecidos no cenário mineiro; ambos com mais de 60 anos de existência (dotados da marca distintiva da tradição), mas também estádios que não passaram pelo processo de modernização. Os jogos analisados foram aqueles em que Guarani e Villa estavam jogando em seus respectivos estádios. Como meio de coleta de dados, optamos pela aplicação de formulários e pela observação não participante. ${ }^{10}$

A aplicação dos formulários foi realizada nas duas horas que antecederam os jogos em frente aos estádios. Participaram da pesquisa apenas torcedores do Guarani / Villa. Através deste instrumento buscamos verificar como os torcedores se relacionam com seu clube e estádio; quais impressões têm acerca de estádios e arenas; quais suas (possíveis) experiências em arenas; e, seu posicionamento sobre o processo de modernização dos estádios. Para a interpretação dos dados, foi utilizada a análise de conteúdo proposta por Bardin (2011).

As observações foram realizadas na área interna do estádio (nas arquibancadas principalmente), durante a realização dos jogos; e, na área externa (ruas do entorno do estádio) antes dos jogos. Após o término de cada partida as observações feitas eram registradas em caderno de campo. Este instrumento teve como finalidade registrar os hábitos e comportamentos dos torcedores nos dias de jogos dentro e fora do estádio.

\footnotetext{
${ }^{9}$ Farião e Castor Cifuentes estão situados respectivamente nas cidades de Divinópolis e Nova Lima.

${ }^{10}$ Este estudo passou pela aprovação do Comitê de Ética em Pesquisa (COEP) da Universidade Federal de Minas Gerais (UFMG) - CAAE 50835115.7.0000.5149 - e respeitou todas as normas estabelecidas pelo Conselho Nacional de Saúde envolvendo pesquisa com seres humanos.
} 


\section{Resultados e Discussão}

Para melhor visualização e compreensão, os resultados e discussões estão subdivididos em quatro segmentos textuais: Campos de jogo; Villanovenses e bugrinos em campo (perfil socioeconômico); Da relação com o clube e com o estádio; e, Percepção dos torcedores: Estádios versus Arenas. No primeiro tópico serão apresentados e discutidos os dados referentes às observações de campo feitas no Castor Cifuentes e Farião, respectivamente; nos demais, estão presentes os resultados obtidos através dos formulários e a análises dos mesmos, de acordo com cada temática.

\section{Campos de Jogo}

Para o Castor Cifuentes foram realizadas 12 incursões a campo. Além destes jogos, o Villa deteve mais três mandos de campo no período estudado. No entanto, não pode realizar as partidas no Castor Cifuentes por serem jogos televisionados contra os clubes da capital. De acordo com a emissora detentora dos direitos de transmissão, o estádio não oferecia condições adequadas para a realização das filmagens.

Situado próximo ao centro da cidade, as ruas de seu entorno são estreitas, um dos fatores que comprometem a realização de jogos de grande apelo. Há bares disponíveis tanto para torcida da casa, quanto para a torcida visitante; além de ambulantes circundando pelas arquibancadas.

Algumas práticas são constantes na torcida Villanovense. Embora não tenham ocorrido em todas as partidas, nem tenham sido unânimes de toda torcida, foram em grande parte dela: os primeiros torcedores chegam faltando uma hora ou menos para o início da partida; o maior volume de público se concentra nos 15 minutos anteriores ao início do jogo (em alguns casos, depois do apito inicial); poucas mulheres chegam com antecedência (raramente desacompanhadas de algum homem); apesar de vários 
torcedores se identificarem como torcedores de Cruzeiro ou Atlético, poucos são os trajam camisas destes clubes durante os jogos; e, estes torcedores, em sua maioria, não utilizam nenhum meio de transporte para deslocar-se ao estádio; são moradores do bairro.

Nas primeiras incursões o cenário encontrado foi de torcedores animados, muita conversa nas arquibancadas e muita expectativa sobre as perspectivas da equipe para a temporada. Pairava um clima amistoso de confraternização entre conhecidos. Quando os atletas entram em campo as conversas cessam, dando espaço para cânticos de apoio ao Villa. A torcida não parecia familiarizada com os jogadores, indicava não saber seus nomes. Comumente se ouvia a gritos como "corre 2", "volta pra marcar 7", "esse 11 é bom"; em poucos momentos ouvimos jogadores sendo chamados pelo nome.

$\mathrm{O}$ clube possui duas torcidas organizadas ativas: Pavilhão Vermelho e Pele Vermelha. Grupos de dez/doze (aproximadamente) integrantes cada, todos jovens. Levam suas baterias e cantam suas músicas em grande parte do jogo, além de utilizar sinalizadores de fumaça vermelha. Ocupam a porção direita da arquibancada lateral, próximo à linha de meio de campo, ou a arquibancada atrás do gol.

Não presenciamos nenhuma confusão envolvendo estas torcidas, senão suas contribuições para a festa. O clima de rivalidade existente da torcida do Villa com o América-MG fez com que ambas torcidas organizadas do Villa se unissem para entoar o grito de "bicha" para o goleiro do América-MG, sempre que este cobrava o tiro de meta. Essa prática não ocorre nas outras partidas.

O jogo contra o América era aguardado pela torcida. Neste, diferente das outras partidas, nas duas horas anteriores ao apito inicial já havia movimentação de torcedores na porta do estádio. A loja do Villa que fica no interior do estádio da qual até então só 
havíamos visto as portas, estava aberta, vendendo camisas e outros souvenirs da equipe de Nova Lima.

Neste jogo também foram ligadas as caixas de som do estádio, que durante uma hora em que permaneceram ligadas (período entre a abertura dos portões e o início da partida) intercalaram entre: o hino popular do Villa, a marchinha; anúncio de patrocinadores da equipe; e, felicitações às mulheres, afinal era 8 de março. Fomos informados por um torcedor que como este jogo seria televisionado, teríamos a presença da charanga do Villa; que só aparece em jogos nestas condições. De fato ela esteve presente e tocou músicas populares ao longo de todo o jogo.

A torcida do Villa se mostrou muito receptiva aos pesquisadores, fomos reconhecidos e abordados em algumas situações por alguns torcedores com os quais já havíamos conversado em outras ocasiões. Ofereceram-se para ajudar e perguntavam se estávamos conseguindo fazer as entrevistas na quantidade necessária.

Para o Farião foram realizadas sete incursões a campo. Considerando os espaços destinados aos torcedores, o estádio é dividido em dois setores: arquibancada e módulo (arquibancada com alguma proteção contra chuva e/ou sol), cada um com sua entrada e bilheteria. Apesar de haver na construção do estádio distinção entre módulo I e II, na prática isso não acontece. Compra-se ingresso para a arquibancada ou módulo. Chegando pela frente, a entrada da arquibancada está de fronte no canto esquerdo, ao passo que a entrada do módulo está bem centralizada. Os ingressos disponibilizados para as torcidas visitantes são sempre na arquibancada. Entretanto, os pontos de venda internos de alimentos e bebidas se encontram apenas do lado da torcida da casa, obrigando o visitante a "invadir" o espaço da torcida bugrina.

Assim como ocorre em outros estádios, a presença feminina aparece em reduzida quantidade. A divisão entre as torcidas da casa e visitante é feita apenas por 
cordas, ambas permanecendo na mesma arquibancada. Menos de uma dezena de policiais fica responsável resguardar esta divisão. Diferente do que percebemos em Nova Lima, em Divinópolis parcela considerável dos torcedores não utilizam camisas do Guarani nas partidas, muitos trajam camisas de Atlético ou Cruzeiro. Em algumas partidas foi possível identificar, inclusive, torcedores com camisas de times de outras localidades, como Bahia, São Paulo, Barcelona, etc.

Na partida contra o América-MG, antes do início do jogo a torcida visitante se mostrava mais efusiva, cantando e tocando instrumentos. No momento em que os atletas adversários entram em campo, passam a ser hostilizados pela torcida local, mais intensamente do que as outras equipes que jogaram contra o Guarani. Detectamos poucas pessoas desacompanhadas, a maioria assistia às partidas em duplas, trios ou grupos. Duas horas antes do início da partida já era grande o movimento na porta do estádio, considerando se tratar de jogo contra um clube da capital, este poderia ser um comportamento atípico.

Para os torcedores que ficam nas arquibancadas (diferente do módulo) são disponibilizados um banheiro masculino e um feminino, apesar da capacidade deste setor ser próximo a 2 mil pessoas. Visualizamos alguns torcedores portando radinho de pilha nas mãos, alguns não eram pequenos. Apesar de permitido portar rádio, o torcedor é proibido de entrar no estádio com garrafas plásticas de água.

Ainda no jogo contra o América-MG, a torcida organizada Red Bugre entra para o estádio, ocupando a quina do escanteio à esquerda de quem entra. Minutos depois a torcida organizada Guaragolo entra e ocupa o espaço atrás do gol esquerdo. Embora não entrem em campo propriamente dito, ambas já estavam se "preparando" para o jogo na porta do estádio com duas horas de antecedência ao início do jogo. Entenda-se por preparação: bater papo, tocar os instrumentos, comer churrasco e tomar cerveja. 
Aparentemente as duas organizadas do Guarani se respeitam, não foi registrada nenhuma confusão entre elas nas partidas em que estivemos presentes. Diferente do que presenciamos com algumas torcidas das ditas "grandes" equipes brasileiras que brigam entre si. Como exemplo, temos no Cruzeiro a Máfia Azul, que não possui um bom relacionamento com a Pavilhão Independente. Apesar de haver exemplos negativos dentro de um mesmo clube, a Guaragolo, formada por torcedores ligados às organizadas do Cruzeiro, e, a Red Bugre, formada por torcedores ligados às organizadas do Atlético, convivem em paz em prol do bem comum, o Guarani.

Durante as partidas é recorrente os torcedores estarem atentos às notícias dos jogos de Cruzeiro e/ou Atlético que, em várias ocasiões, jogam nos mesmos dias/horários do bugre. Não a toa que dentro do estádio há venda de camisas oficiais de Cruzeiro e Atlético. Em jogo contra o Atlético-MG foi possível identificar algumas peculiaridades, como filas imensas para entrar; o esgotamento de todos os ingressos; grande movimentação de torcedores na porta do estádio por parte das duas torcidas nas duas horas antecedentes ao jogo; policiamento reforçado; e, torcedores do Atlético (trajando camisas) no meio da torcida destinada ao Guarani.

Não houve divisão das torcidas nesta partida, entretanto, as torcidas organizadas do Atlético ficaram restritas ao espaço normalmente destinado às torcidas visitantes. A divisão dos "setores" foi feita com cordas, como de costume, mas considerando que o espaço destinado aos visitantes não conta com banheiros, nem com lanchonetes, foi comum ver alguns torcedores da principal organizada do Atlético circulando em meio à torcida do bugre.

\section{Villanovenses e Bugrinos em Campo}

Para a exibição dos resultados obtidos através dos formulários, utilizamos a seguinte estratégia: os dados foram comparados em dois distintos grupos: TG - 
Torcedores do Guarani e TV - Torcedores do Villa. Nas questões em que agrupar os resultados de TG e TV não resultou em prejuízo na análise, optamos por apresentá-los através de um terceiro grupo - TGV - Torcedores de Guarani e Villa. Nas questões abertas, os torcedores eram incentivados a argumentar livremente, apontando tantos elementos quanto fossem necessários. A figura 1 apresenta informações referentes ao perfil socioeconômico dos torcedores,

\section{Figura 1: Perfil socioeconômico dos torcedores}

\begin{tabular}{|l|r|r|r|}
\hline & \multicolumn{1}{|c|}{ TG } & \multicolumn{1}{c|}{ TV } & \multicolumn{1}{c|}{ TGV } \\
\hline Homens & 49 & 53 & 102 \\
\hline Mulheres & 0 & 5 & 5 \\
\hline Total & 49 & 58 & $\mathbf{1 0 7}$ \\
\hline
\end{tabular}

Em relação a renda mensal (TG)

Maior frequência: entre 1 e 2 salários mínimos (42,86\%)

Menor frequência: entre 4 e 5 salários mínimos (4,08\%)

Renda acima de 5 salários mínimos: $8,16 \%$

Renda até 2 salários mínimos: $48,98 \%$

Em relação a renda mensal (TV)

Maiores frequências: entre 2 e 3 salários mínimos (17,24\%); e, entre 5 e 7 (17,24\%)

Menor frequência: entre 4 e 5 salários mínimos (1,72\%)

Renda acima de 5 salários mínimos: $34,48 \%$

Renda até 2 salários mínimos: $20,69 \%$

Em relação a renda mensal (TGV)

Maior frequência: entre 1 e 2 salários mínimos (27,1\%)

Menores frequências: entre 4 e 5 salários mínimos (2,8\%); e, entre 9 e $11(2,8 \%)$

Optou por não responder: $16,8 \%$

Parte dos torcedores $(16,8 \%)$ optou por não responder a questão sobre renda, assim, estamos atentos à possibilidade deste fato ter mascarado, até certa medida, os resultados obtidos. Podemos perceber um maior poder de compra na TV quando comparado a TG ao analisar as frequências obtidas de torcedores com renda de até 2 salários mínimos e, a partir de 5 salários mínimos.

\section{Da Relação com o Clube e com o Estádio}

Perguntamos aos participantes se acompanhavam os jogos da equipe para qual torcem, a maior frequência encontrada foi da resposta positiva $(97,2 \%){ }^{11}$. Em seguida,

${ }^{11} \mathrm{TG}-97,96 \%$; TV - 96, 55\%. 
perguntamos a frequência em que iam ao estádio quando de jogos de seu clube, oferecendo as seguintes opções: sempre, frequentemente, raramente e primeira vez. A maior frequência encontrada foi de torcedores que vão sempre (71\%), a menor, de torcedores que iam pela primeira vez $(2,8 \%)$.

Para $87,76 \%$ da TG e $89,66 \%$ da TV o ato de ir ao estádio surge como uma prática recorrente (somando sempre e frequentemente), dotada de tradições e simbolismos.

Os dados sugerem que para o grupo estudado, o estádio se constitui enquanto um espaço apropriado, ou seja, um lugar. Embora haja distinção de significados entre as terminologias 'espaço' e 'lugar', não há consenso na literatura para suas definições. De tal forma, adotamos aqui a compreensão do espaço na qualidade de um conceito abstrato, o qual se realiza no plano do concreto enquanto lugar de realização da vida humana (CARLOS, 2001). Quando tratamos o estádio como espaço, conferimos um sentido deste enquanto um objeto geográfico, uma construção humana que compõe a paisagem da cidade. Quando tratados como lugar, indicamos uma relação de maior proximidade, maior interação.

O espaço é um requisito necessário, um instrumento e um produto da interação da sociedade em toda sua complexidade. Ao dar sequência à sua existência, a sociedade reinventa o espaço. Podemos compreendê-lo sob a égide de duas dimensões: da localização, enquanto um ponto pertencente ao mapa e do conteúdo desta localização, isto é, aquilo que torna um lugar único e lhe confere valor. Este, atribuído por meio das práticas sociais que ali ocorrem em função da apropriação dos espaços. Assim, são a presença humana e as interações decorrentes dela, que outorgam a noção de lugar a um dado espaço (CARLOS, 2001). 
Para conferir o sentido de lugar a um dado espaço, dois elementos são essenciais: valor e tempo (TUAN, 1983). Através das experiências no espaço, sejam elas sensoriais ou emotivas, que o mesmo pode ser dotado de valor e assumir caráter de lugar na vida dos sujeitos. Como afirmou Yi-Fu Tuan, "experiência é um termo que abrange as diferentes maneiras através das quais uma pessoa conhece e constrói a realidade" (TUAN, 1983, P.9). Para se viver estas experiências é necessário tempo. Dessa forma, a relação tempo-espaço surge de forma indissociável decorrente das ações humanas, as quais se concretizam por meio da apropriação (CARLOS, 2001).

Para avançar na construção do entendimento destes dois conceitos, devemos destacar que o espaço é muito mais que um "vazio", é a condição primordial para a realização das atividades sociais. O espaço apropriado materializa a reprodução de determinadas relações sociais, ao passo que a vida se constitui em lugares destinados a estes fins (CARLOS, 2007). O torcedor pode acompanhar o seu clube em todos os estádios em que este for jogar como visitante, e se apropriar deste espaço, exercer seu "papel de torcedor". Entretanto, o seu lugar vai continuar sendo o estádio onde a equipe manda seus jogos.

Questionamos os participantes se os mesmos buscavam notícias relativas ao seu clube. Dentre os que responderam positivamente $(91,6 \%)^{12}$, perguntamos onde buscavam as informações; esta foi uma questão aberta.

Para a TG as formas mais recorrentes de acompanhar as notícias do clube foram (em ordem decrescente de frequência): ouvindo programas esportivos pelo rádio, através da internet e, assistindo programas esportivos pela televisão; para a TV foram: através da internet, ouvindo programas esportivos pelo rádio e, lendo jornais impressos. Podemos perceber como os meios de comunicação exercem um importante papel na

\footnotetext{
${ }^{12} \mathrm{TG}-85,71 \%$; TV $-96,55 \%$.
} 
circulação das notícias, embora maneiras alternativas como "ir à sede" e "conversar com os amigos" tenham surgido com considerável frequência.

Os clubes/estádios periféricos, embora muitas vezes estejam situados nas periferias das grandes cidades, aqui não estão sendo analisados pela sua localização geográfica. Nossa compreensão se encaminha no sentido destes estarem às margens da atenção midiática de uma forma geral, sejam elas impressas, televisivas, digitais, etc. Isto é, trata-se de clubes não pertencentes à chamada "elite do futebol brasileiro" ou, "série A". A mídia esportiva notadamente direciona-se para os clubes da série A do campeonato brasileiro. A série B adquire maior importância (ainda que direcionada a equipes específicas) à medida que clubes de grande torcida pelo Brasil disputam a divisão, como ocorrido em 2013 (Palmeiras), Internacional (2017) e Sport (2019), por exemplo.

Não obstante o principal campeonato nacional possua quatro divisões, as duas últimas ganham pouca repercussão nos programas esportivos, jornais impressos, e sites esportivos de maior veiculação. O aumento no volume de informações ocorre normalmente na reta final das competições. Corroboramos com Leda Costa (2015) ao afirmar que, para tais mídias, o "futebol brasileiro" se resume a seleção e a alguns poucos clubes (bem como seus torcedores) dominantes e 'aspirantes' aos títulos estaduais, nacionais, continentais, e intercontinentais, a cada temporada esportiva.

As mídias esportivas questionam o baixo nível dos campeonatos estaduais, responsabilizando os clubes periféricos que, possuem baixa qualidade técnica, elencos fracos, estádios precários, gramados ruins, etc. Como "consequência" desse cenário, apontam o baixo público presente nos estaduais. A lógica mercadológica atual privilegia os principais clubes do Brasil, em detrimento dos demais. Um importante destaque 
nesse sentido percebemos com relação às cotas dos direitos televisivos repassadas aos clubes, consideravelmente destoantes (COSTA, 2012).

Tais desigualdades ocorrem inclusive entre os clubes considerados "grandes". Considerando o ano de 2018, para os direitos televisivos do campeonato nacional, temos clubes como Corinthians e Flamengo com receita de R\$ 170 milhões (cada); Cruzeiro, Atlético-MG, Internacional, Grêmio, Botafogo e Fluminense com R\$ 60 milhões (cada); e, América-MG, Ceará e Paraná com R\$ 23 milhões (cada) ${ }^{13}$. No campeonato estadual de 2018, os "quatro grandes" do estado de São Paulo receberam das emissoras televisivas $\mathrm{R} \$ 17$ milhões (cada); Cruzeiro e Atlético-MG receberam $\mathrm{R} \$$ 12,3 milhões (cada); e, clubes periféricos como Villa Nova-MG, R \$ 850 mil (cada) ${ }^{14}$. Não nos causa espanto que os clubes periféricos, com orçamentos tão enxutos, tenham que lutar tanto para subexistir.

Evidencia-se assim, que tais equipes não disponham de meios financeiros para arcar com a formação de elencos competitivos, reformas no estádio, melhoria do gramado, oferecer uma estrutura adequada para os seus torcedores. Dessa forma, o "baixo nível” dos estaduais deveria servir de norte para que soluções sejam pensadas para resolver as questões abordadas. Entretanto, a "solução" muitas vezes proposta, diz respeito à redução do número de clubes na competição e/ou vetos a realização de jogos de maior apelo nos estádios periféricos. As mudanças precisam ocorrer, entretanto, não deveriam ser realizadas de forma tão reducionista como as alternativas propostas (COSTA, 2012).

Assim, vemos em meio à mercantilização do futebol brasileiro, tentativas desenfreadas de exclusão não apenas dos torcedores, mas também dos clubes; sem que

\footnotetext{
13 Disponível em: https://infograficos.gazetadopovo.com.br/esportes/cotas-de-tv-da-globo-para-obrasileirao-2018/. Acesso em: 20 maio 2019.

14 Disponível em: http://blogs.diariodepernambuco.com.br/esportes/2018/01/05/as-cotas-de-tv-dosmaiores-estaduais-de-2018-com-r-306-milhoes-para-119-times/. Acesso em: 20 maio 2019.
} 
ao menos se busque soluções para as causas de tamanhas desigualdades. O debate centra-se em tentativas de remover os problemas, ao invés de resolvê-los. Essa postura em nada contribui para avançar os - necessários - debates sobre a cultura do futebol brasileiro. Seguimos com muitos clubes/estádios sucateados em detrimentos de alguns poucos que estampam as capas de jornais, revistas, sites (COSTA, 2012).

No entanto, esses clubes/estádios periféricos constituem importante parte da história do futebol brasileiro. O torcer nos clubes que não frequentam grandes competições, não disputam títulos nacionais e internacionais (efetivamente) e, às vezes sequer figuram na principal divisão dos torneios estaduais, adquire suas próprias configurações. Uma dessas particularidades é o torcer por duas equipes, fenômeno comum que pode ser observado nas torcidas periféricas (tal como observado nas torcidas dos clubes estudados) onde vemos torcedores trajando camisas de outros clubes, principalmente da capital (COSTA, 2015).

À medida que o futebol é tratado mercadologicamente como um produto, se manter "no mercado" e atrair os torcedores não é tarefa simples para os clubes sem projeção midiática (COSTA, 2015). Torcer por outra equipe, mais competitiva no que tange a disputa por títulos, "compensa" a baixa representatividade dos clubes periféricos no cenário esportivo. Outra particularidade refere-se às expectativas que a equipe delineia a cada temporada. São corriqueiramente limitadas. Embora a torcida tenha consciência destas limitações, isso não impede que os mais fiéis torcedores acompanhem o clube independente da divisão que esteja. Por vezes a meta da equipe é se classificar para a uma próxima fase de um determinado torneio. Os longos períodos sem partidas no decorrer do ano (considerando que algumas equipes disputam apenas os torneios estaduais) pesam nos cofres dos clubes (COSTA, 2015). 
Embora Villa e Guarani sejam equipes já tradicionais no cenário mineiro, o risco de falência nunca se esvanece. O Villa por pouco deixou de disputar uma edição da Série D por falta de verba para arcar com despesas de transporte do plantel; e, o Guarani esteve a ponto de perder seu estádio por não quitar dívidas.

Desde a eliminação da seleção brasileira na Copa do Mundo de 2014, pela seleção alemã, muito se fala em "reformulação do futebol brasileiro". Entretanto, soa estranho analisar profundamente algo conhecido de forma tão generalista como o futebol. Acreditamos que parte dessa renovação carece de um "olhar para esse futebol buscando nele sua diversidade, oferecendo suporte para manutenção e crescimento de clubes que embora possam estar longe do circuito principal são parte constitutiva do futebol nacional" (COSTA, 2015, s/p).

\section{Percepção dos Torcedores: Estádios versus Arenas}

Com o intuito de analisar a percepção que os torcedores de estádios periféricos têm sobre estádios e arenas, fomentamos três questões iniciais. Na primeira um breve diálogo para identificar a existência de conhecimento prévio dos participantes com relação às reformas/construções de estádios/arenas que ocorreram em função da Copa do Mundo de 2014. Utilizamos como referência a reforma do Mineirão, Maracanã e a construção da Arena Itaquera (96,3\% responderam positivamente) ${ }^{15}$. Constituiu-se enquanto questão aberta, na qual utilizamos das categorias para apresentar os resultados.

Para TGV as principais compreensões apresentadas em ordem decrescente de frequência, foram: 1) conforto e segurança - caracterizada por melhorias para os torcedores, principalmente no que tange ao aumento do conforto e da sensação de segurança. 2) desenvolvimento do futebol - definida por melhorias e/ou avanços para o futebol brasileiro de maneira geral, dando ênfase ao aumento da receita dos clubes. 3)

\footnotetext{
${ }^{15}$ TG $-97,96 \%$; TV - 94,83\%.
} 
infraestrutura - designada por melhorias físicas na infraestrutura dos estádios de forma geral, colocação de cadeiras nas arquibancadas, melhorias nos acessos do estádio. 4) corrupção - caracterizada por desvio e desperdício de dinheiro público. 5) decadência do futebol - definida em seu sentido mais amplo, causa de não haver mais bons jogadores atuando no Brasil, endividamento dos clubes e torcida menos festiva nas arenas. 6) elitização - designada pela exclusão dos torcedores de menor poder aquisitivo dos estádios.

Além dessas categorias, algumas falas isoladas chamaram nossa atenção. Precisamos ter cautela com alguns discursos muito entusiasmados, muito inflamados. Temos como exemplo:

Crescimento cultural do brasileiro, mostrar o certo, o novo modelo de rentabilidade para os clubes (TG\#4, masculino, 30 anos).

Como disse Nelson Rodrigues, o brasileiro em seu "complexo de vira-lata". Pensamos neste trabalho que o status de uma tendência importada dos grandes centros mundiais, como Europa e Estados Unidos assume no imaginário popular, especificamente no caso brasileiro, uma denotação quase sempre positiva. Por vezes, sem que haja reflexão sobre o assunto. O Brasil produz coisas positivas e negativas, assim como Europa e Estados Unidos. Os próprios conceitos de ‘positivo’ e ‘negativo' não são consensuais. Portanto, não consentimos com a ideia de que, incorporar um modelo externo, seja por si, o 'crescimento cultural do povo brasileiro'.

$\mathrm{Na}$ segunda questão perguntamos se percebiam diferenças entre estádios e arenas $\left(82,2 \%\right.$ responderam positivamente) ${ }^{16}$. Também se constituiu enquanto questão aberta. Tanto para TG quanto para TV, as principais compreensões apresentadas em ordem decrescente de frequência, foram: 1) conforto e segurança - caracterizada por

\footnotetext{
${ }^{16}$ Para os demais $(17,8 \%)$, o preenchimento do formulário se encerrou neste ponto; TG - 77,55\%; TV $86,21 \%$.
} 
melhorias para os torcedores, principalmente no que tange ao aumento do conforto e da sensação de segurança.

Clube lucra mais com isso (arena), porque oferece mais conforto e segurança (TG\#24, masculino, 49 anos).

A acessibilidade, ângulo de visão, conforto, cadeiras, é tudo melhor na arena (TV\#66, feminino, 63 anos).

Maior segurança e conforto na arena melhora a qualidade do espetáculo (TV\#14, masculino, 34 anos).

2) Infraestrutura e organização - definida por melhorias físicas na infraestrutura dos estádios de forma geral, organização espacial, colocação de cadeiras nas arquibancadas, melhorias nos acessos do estádio, presença de funcionários para orientar os torcedores, etc.

\footnotetext{
$\mathrm{Na}$ arena é tudo certinho, tem cadeira numerada, tudo é organizado e limpinho (TG\#80, masculino, 45 anos).

A arena é menor que o estádio, e fica mais vazio (TV\#96, feminino, 28 anos). Arena não tem a 'geral', era o lugar do povão (TV\#55, masculino, 68 anos).
}

A extinção da geral nas novas arenas não passou despercebida pelos torcedores, na perspectiva de ser considerado como um dos espaços mais democráticos dentro dos estádios.

3) futebol versus espetáculo - designada no sentido das arenas serem espaços multiuso, enquanto os estádios são exclusivamente espaços dedicados ao futebol.

Estádio é para jogar futebol, arena é shopping (TG\#7, masculino, 51 anos).

Arena possui vários usos, estádio é específico para futebol (TV\#31, masculino, 21 anos).

Para aqueles que percebiam diferenças, perguntamos na terceira questão se o Farião/Castor (de acordo com a cidade) seria um estádio ou arena. Para os que disseram se tratar de um estádio (83\%), perguntamos se numa eventual reforma que o 
transformasse em arena, seriam favoráveis ou contrários. Os resultados obtidos foram: 79,5\% favoráveis, 19,2\% contrários e 1,4\% não souberam opinar.

Nesse sentido, perguntamos aos torcedores o porquê da escolha. Entre os favoráveis, para TGV as principais motivações apresentadas foram: 1) o clube relacionada ao aumento da receita, portanto, positivo. 2) a torcida - definida por usufruir de maior conforto durante os jogos. 3) a cidade - designada por aumentar sua visibilidade a nível nacional e atrair maiores investimentos. Entre os contrários, para TGV as principais motivações foram: 1) elitização - relacionada ao fato de que com a elitização dos torcedores, alguns torcedores não poderiam mais frequentar o estádio. 2) tradição - definida pelo "jeito" de torcer que seria modificado, visto que os torcedores teriam que se comportar melhor.

Mais renda para o time melhorar a estrutura. Mais famílias, crianças e idosos indo ao estádio (TG\#37, masculino, 34 anos).

Enquanto o estádio for este, o Villa será pequeno. Ele limita o crescimento do time (TV\#94, masculino, 29 anos).

Afastaria o verdadeiro torcedor, igual aconteceu em Belo Horizonte (Mineirão) (TG\#24, masculino, 49 anos).

Tira o romantismo do futebol, futebol precisa de arquibancada, de alambrado (TG\#27, masculino, 39 anos)

O clube merece uma arena condizente com a sua tradição (TV\#18, masculino, 70 anos).

O interesse dos torcedores pela construção de uma arena moderna centra-se no "bem do clube", e não essencialmente no "bem da torcida". Diante os dados apresentados e discutidos até aqui, percebemos que de maneira geral, para TGV as diferenças entre estádios e arenas, bem como as normas de condutas que regem cada um desses espaços, parecem estar claras.

Para saber se os torcedores possuíam alguma vivência em arenas, mesmo que mínima, ou se opinavam com base em outras vias, que não as suas próprias experiências, questionamos se já haviam assistido partidas de futebol nas novas arenas 
multiuso $\left(83,9 \%\right.$ responderam positivamente) ${ }^{17}$; Deste total, $82,2 \%$ sinalizaram pelo Mineirão.

Nesse sentido, perguntamos aos torcedores os pontos positivos e negativos observados na(s) arena(s). Para TGV os principais destaques positivos foram: 1) conforto/segurança. 2) estrutura/organização. Na TV ainda surgiu uma terceira categoria, embora com baixa frequência: 3) ausência de pontos positivos.

Os pontos negativos para TGV foram: 1) estacionamento - relacionada à redução do número de vagas disponíveis no estádio e, a grande distância dos estacionamentos alternativos. 2) nenhum. 3) altos custos - designada pelos altos valores dos ingressos e alimentos no estádio. 4) extinção da geral - associada à redução da capacidade de público. 5) alimentos - relacionada a baixa qualidade dos alimentos comercializados dentro das arenas. 6) organização - designada a insatisfação com a organização, pois alegam faltar funcionários capacitados para dar informações corretas. 7) controle - associada às restrições impostas aos torcedores, por meio de outros torcedores que mandam se assentar e pelos seguranças privados que solicitam que tirem os pés das cadeiras.

No estudo realizado por Priscila Campos (2016), os resultados encontrados foram similares. Os três aspectos melhores avaliados pelos torcedores após a reforma do Mineirão foram conforto, segurança e organização. Por outro lado, no que se refere aos aspectos negativos da reforma do estádio, foram apontados que, estacionamento, ingresso e alimentação estavam entre as principais reclamações. Dando ênfase a questão do valor dos ingressos e alimentação, a autora destacou a representatividade da insatisfação com o estacionamento nos resultados.

\footnotetext{
${ }^{17} \mathrm{TG}-76,32 \%$; TV $-89,8 \%$.
} 
A última questão teve como finalidade investigar se os torcedores percebem que o fato de estar em uma arena ou em estádio interfere no comportamento da torcida durante os jogos. A maior frequência foi de torcedores que acreditam nessa interferência $(56,3 \%)^{18}$.

Por fim, perguntamos como esta interferência pode acontecer. Para TGV houve uma ideia central: vigilância - pautada na ideia que na arena o torcedor é mais comportado ${ }^{19}$ porque tem regras, dessa forma é mais seguro que o estádio.

Arena é mais rígido, a pessoa perde a liberdade de torcer. Na arquibancada (estádio) é diferente (TG\#27, masculino, 39 anos).

Em proporção inferior, surgiram duas outras categorias, para ambas torcidas: 1) festa - associada pela concepção de que na arena tem menos festa da torcida, menos utilização de bandeiras e sinalizadores. 2) apoio - centrada na visão de que na arena a torcida demonstra mais apoio ao clube.

Campos (2016) ao analisar as formas de uso e apropriação do Mineirão, após a sua conversão em arena, percebeu que a adoção de uma Parceria Público-Privada (PPP) para gerenciar o estádio, o transformou em uma empresa. Como tal, o espaço assumiu um papel atuante na busca por capital de investimento. Passando a ter regras mais rigorosas, tanto no trato com os torcedores quanto com os clubes. Se aqui falávamos em torcedores-consumidores, nesse processo os clubes também se tornaram alvos do mercado. Por esta ótica, o clube se torna mais um cliente desse mercado. Assim que, estes espaços são cada vez mais transformados em mercadorias e a sua apropriação ocorre na perspectiva do consumo.

\footnotetext{
${ }^{18} \mathrm{TG}-55,26 \%$; TV $-57,14 \%$.

${ }^{19}$ Os participantes desta pesquisa sugeriam que esse torcedor "comportado", assim o é, pelas repressões que ocorrem dentro do estádio e pelo público mais elitizado, mais "família". Portanto se ouvem menos xingamentos e os torcedores assistem aos jogos sentados.
} 
Arlei Damo (2013) também nos alertou para o processo de elitização em curso nas arenas multiuso, talvez a temática que gere a maior controversa no que diz respeito à modernização dos estádios. Não podemos esquecer que além das doze arenas que foram utilizadas para a Copa do Mundo de 2014, outros (as) estádios/arenas vêem paulatinamente sofrendo com a redução de sua capacidade. A redução da oferta, leva ao aumento dos valores cobrados para se assistir aos jogos nas arenas "padrão FIFA".

Uma das ferramentas utilizadas para a redução da capacidade dos estádios foi à extinção do setor conhecido como "geral”. Espaço mais popular e democrático, próximo ao campo, e que normalmente se destinava aos torcedores com menor poder de compra. Incrementado com cadeiras confortáveis e com uma visão privilegiada do espetáculo, tal espaço se tornou um dos mais valorizados nas novas arenas.

Em termos de receita para os clubes, o aumento no valor dos ingressos não apenas compensou a redução de público, como projetou maior lucratividade. Afinal, espera-se que um público economicamente favorecido consuma outros produtos que não apenas o jogo em si. Estacionamento e alimentação são integrantes deste hall de mercadorias. Embora não explicitem esta intenção, os gestores das arenas multiuso estão protagonizando um processo de higienização nestes espaços, distanciando os torcedores que consomem pouco ou que causam aborrecimentos. Contudo, a "substituição" do perfil atual pelo perfil "ideal”, almejada pelos administradores, é um processo que pode levar anos (DAMO, 2013).

O que percebemos não é a inclusão de um novo público, é a retirada de outro. Pois, os torcedores que hoje acompanham os jogos de seu clube nas arenas, em grande parcela, já o faziam nos antigos estádios. Embora os gestores desejem interferir no comportamento da torcida, o processo não ocorre sem que haja resistência. 
As arenas multiuso são espaços com vieses homogêneos, limitam os usos e os modos de vida. Por trás dele e de sua intencionalidade, aparentemente neutra, se esconde um sentido político, como meio de dominação (CARLOS, 2001). Contrastante com a maneira que entendemos os estádios de futebol, lugar de lutas e reivindicações sociais, da livre manifestação dos povos. Como consequência, o local se apresenta cada vez mais globalizado, menos diverso, menos identitário.

Tratados como mercadoria, gradativamente os espaços têm seus valores estabelecidos pela lógica econômica, um processo que elimina a durabilidade das relações e promove um esvaziamento dos valores sociais. Assim que, as formas de apropriação e de uso dos espaços, se sujeitam, em escala crescente, aos interesses do capital. Estamos diante de um severo processo que deforma identidades e restringe os corpos, onde o valor de troca predomina sobre o valor de uso dos espaços. Uma tendência crescente no mundo globalizado (CARLOS, 2001).

Com os estádios, vemos que a tendência de globalização de um modelo considerado mais "adequado" de apropriação e uso dos espaços está posta. Surgida na Inglaterra, difundida pela Europa, enfim, pelo restante do mundo. Chegou ao Brasil tendo no estado do Paraná plantada sua primeira raiz, com a reformulação do estádio do Clube Atlético Paranaense. Vivemos tempos líquidos, em que predomina o supérfluo, o reciclável, o momento, em que cada vez mais o modelo hegemônico se difunde.

Os indivíduos se reconhecem nos espaços onde circulam, onde estabelecem relações, se organizam, e assim, formam sua identidade enquanto torcedores. Para isso, o sentir, o cheirar, o tocar, o ouvir, se tornam importantes elementos para se experimentar e vivenciar o espaço ao longo do tempo. Entretanto, o processo de mercantilização dos espaços acarreta na modificação da relação tempo-espaço, inserindo uma nova lógica na relação dos indivíduos com os espaços, uma lógica que 
não respeita as particularidades do local. Pelo contrário, busca impor a lógica global formando assim, as identidades abstratas (CARLOS, 2001).

\section{Considerações Finais}

Lidamos com torcedores que acompanham os jogos do clube, indo constantemente ao estádio. Inclusive, sendo esta a principal forma apontada para acompanhar a equipe. A relação dos TGV com o clube é marcada por uma aliança que denota compromisso e amor.

Percebemos que de maneira geral, para TGV as diferenças entre estádios e arenas, bem como as normas de condutas que regem cada um desses espaços, parecem estar claras. Houve por parte dos participantes a compreensão de que arenas são projetadas para oferecer conforto e sensação de segurança, ao passo que os estádios não.

Conforme apresentado, os dois clubes têm propostas para aquisição de Arenas. Reformulação do Farião no caso do Guarani, e a construção de um novo espaço no caso do Villa. Aliado a isso, os dados mostram que os torcedores também são favoráveis a estas transformações, as quais ainda não ocorreram em decorrência da falta de recursos financeiros que viabilizassem as obras. O que nos leva a duas importantes questões.

Os torcedores estão conscientes dos impactos que tais modificações podem ocasionar ou estão influenciados pelos discursos miditáticos aos quais são bombardeados cotidianamente que colocam as arenas em "pedestais" como um bem "necessário" para o sucesso dos clubes? Porque mesmo cientes de todos os pontos negativos abordados, correndo inclusive o risco da exclusão da vivência cotidiana nestes espaços, os torcedores estão dispostos a se submeter a tal processo? Não temos elementos suficientes para responder estas duas questões, mais investigações serão necessárias para responder às novas questões que surgiram ao final das análises. 
As interações entre os sujeitos, seus tempos e espaços, e o torcer são de difícil compreensão e essa pesquisa de modo algum esgota as possibilidades de análise desses fenômenos. Entretanto, dá luz a muitas informações relevantes sobre as relações do torcer estabelecidas nesses estádios, ao mesmo tempo em que levanta novas questões e apontam para outras possibilidades de trabalho.

Tivemos o intento de resgatar a importância de refletir sobre os aspectos envolvidos nestas transformações, para assim, respeitar a constituição dos modos de torcer tão característicos do povo brasileiro, em toda sua complexidade. Visando garantir sua continuidade.

\section{REFERÊNCIAS}

BARDIN, Laurence. Método: organização da análise. In: Análise de conteúdo. São Paulo: Edições 70, 2011. p. 123-131.

CAMPOS, Priscila Augusta Ferreira. As formas de uso e apropriação do estádio Mineirão após a reforma. 2016. 313 f. Tese (Doutorado em Educação Física) Faculdade de Educação Física, Universidade Estadual de Campinas, Campinas, 2016.

CARLOS, Ana Fani Alessandri. O espaço e o tempo sociais no cotidiano. In: $\mathbf{O}$ Espaço Urbano: novos escritos sobre a cidade. São Paulo: FFLCH, 2007. p. 49-54. Introdução. In: Espaço-tempo na metrópole: a fragmentação da vida cotidiana. São Paulo: Contexto, 2001. Cap. 1, p. 11-44.

COSTA, Leda Maria da. Futebol para poucos. Ludopédio. 2012. Disponível em: https://www.ludopedio.com.br/arquibancada/futebol-para-poucos/. Acesso em: 01 jul. 2016.

Vesti uma camisa e saí por aí: Madureira x CRB e os futebóis do Brasil. Ludopédio. 2015. Disponível em: http://www.ludopedio.com.br/arquibancada/vestiuma-camisa-listrada-e-sai-por-ai-madureira-X-crb-e-os-futebois-do-brasil/. Acesso em: 01 jul. 2016.

CURI, Martin. A disputa pelo legado em megaeventos esportivos no Brasil. Horizontes Antropológicos, Porto Alegre, n.40, p.65-88, jul-dez. 2013.

DAMO, Arlei Sander; OLIVEN, Ruben George. O Brasil no horizonte dos megaeventos esportivos de 2014 e 2016: sua cara, seus sócios e seus negócios. Horizontes Antropológicos. Porto Alegre, n.40, p.19-63, jul-dez. 2013. 
FREITAS, Wagner Augusto Álvares de. Villa Nova: 100 anos de glórias em vermelho e branco. Belo Horizonte: Edição do autor, 2008. 613 p.

MASCARENHAS, Gilmar. "Não vai ter arena": futebol e direito à cidade. Revista Advir. Rio de Janeiro, n.32, p.24-38, jul-dez. 2014.

TUAN, Yi-Fu. Perspectiva Experencial. In: Espaço e Lugar: a perspectiva da experiência. São Paulo: DIFEL, 1983. p. 9-21.

\section{Endereço dos Autores:}

Christian Matheus Kolanski Vieira

Endereço Eletrônico: christian_kolanski@hotmail.com

Sílvio Ricardo da Silva

Endereço Eletrônico: prof.srs@ @mail.com 